\title{
FUNGSI FORUM KOORDINASI PEMERINTAHAN DAERAH (FORKOPIMDA) DALAM SISTEM PEMERINTAHAN DAERAH DI INDONESIA
}

\author{
Oleh: \\ Sri Maulidiah \\ Program Studi Ilmu Pemerintahan \\ Fakulas Ilmu Sosial dan Ilmu Politik \\ Universitas Islam Riau \\ Sri.ip@soc.uir.ac.id
}

\begin{abstract}
Abstrak
Pemerintahan daerah bersama-sama dengan Dewan Perwakuilan Rakyat daerah (DPRD) menyelenggarakan pemerintahan daerah dan dibantu oleh unsur perangkat daerah terkait dengan penyelenggaraan urusan yang menjadi kewenangan dari pemerintah daerah. Dalam penyelenggaraan pemerintahan daerah unsur pemerintah daerah bersama-sama dengan Dewan Perwakilan Rakyat Daerah menyelenggarakan pemerintahan daerah dan dibantu oleh unsur perangkatdaerah terkait dengan penyelenggaraan urusan yang menjadi kewenangan dari pemerintah daerah. Dalam urusan-urusan tertentu, pemerintah daerah dibantu olehunsur-unsur lain seperti instansi vertikal yang ada di daerah, dalam bentuk penyelenggaraan urusan umum pemerintahan dan urusan sisa lainnya. Sehubungan dengan hal tersebut, dalam Undang-Undang Nomor 23 tahun 2014 tentang Pemerintahan Daerah perlu dibentuk suatu wadah yang disebut dengan Forum Koordinasi Pimpinan Daerah atau yang disingkat dengan FORKOPIMDAForum Koordinasi Pimpinan Daerah dibentuk berdasar Undang-Undang Nomor 23 tahun 2014 tentang Pemerintahan Daerah. Secara historis Forum Koordinasi Pimpinan Daerah dahulunya dalam bentuk Musyawarah Pimpinan Daerah atau yang disingkat MUSPIDA, Fungsi Forkopimda adalah untuk menunjang pelaksanaan urusan pemerintahan umum oleh pemerintah daerah Kegiatan yang terkait dengan FORKOPIMDA dibiayai memalui Anggaran pendapatan dan Belanja Negara. Disarankan kepada pemerintah untuk secepatnya mengeluarkan peraturan pemerintah tentang FORKOPIMDA. Disarankan kepada daerah Provinsi dan Kabupaten/Kota untuk berinisiatif dalam menanggulangi biaya penyelenggaraan urusan pemeritahan umum. Disarankan kepada pemerintah untuk secepatnya mengeluarkan peraturan pemerintah tentang FORKOPIMDA serta kepada Dinas Provinsi dan Kabupaten/Kota.
\end{abstract}

Kata Kunci: Pemerintahan, Pemerintah Daerah, FORKOPIMDA, MUSPIDA 


\begin{abstract}
Local government together with the Regional Perwakuilan Rakyat (DPRD) held local government and assisted by elements of regional tools related to the implementation of the affairs that become the authority of local government. Inthe implementation of regional government elements of local government togetherwith the Regional People's Legislative Assembly to organize local government and assisted by elements of regional tools related to the implementation of the affairs that become the authority of local government. In certain matters, the local government is assisted by other elements such as vertical institutions in the region, in the form of the administration of public affairs and other residual matters. In this regard, in Law No. 23 of 2014 on Regional Government, a forum called the Coordination Forum for Regional Leaders or shortened with FORKOPIMDA should be established. FORKOPIMDA formerly called this element of deliberation of regional leadership or abbreviated with MUSPIDA. in carrying out its function FORKOPIMDA still find various problems, such as budgetary sources, management FORKOPIMDA, organizational structure, and so forth. The Regional Leadership Coordination Forum was established based onLaw Number 23 of 2014 on Regional Government. Historically the Regional Leadership Coordination Forum was in the form of a Regional Leadership Council or abbreviated as MUSPIDA, the function of Forkopimda is to support the implementation of general government affairs by local governments Activities associated with FORKOPIMDA are funded through the State Budget and Expenditure Budget. It is suggested to the government to immediately issue a government regulation on FORKOPIMDA. It is recommended to Provincial and District / City region to take initiative in tackling the cost of organizing general government affairs. It is advisable to the government to immediately issue a government regulation on FORKOPIMDA and to Provincial and District / City Offices.
\end{abstract}

Keywords: Government, Local Government, FORKOPIMDA, MUSPIDA

\section{Latar Belakang}

Pemerintah pada hakekatnya melaksanakan 2 (dua) fungsi yakni fungsi mengatur dan an fungsi mengurus, fungsi mengatur artinya

pemerintah diberikan kewenangan untuk membuat aturan-aturan dalam bentuk peraturan perundangundangan. Sedangkan fungsi

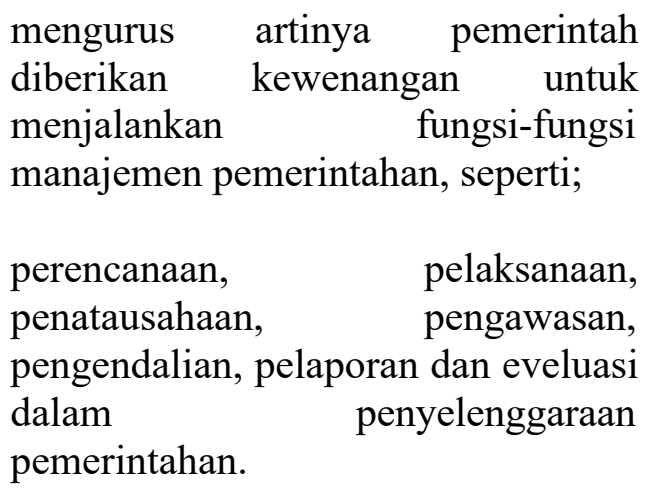


Begitu juga dengan pemerintah daerah, juga memiliki fungsi untuk mengatur dan mengurus, sehingga pemerintah daerah juga dapat membuat peraturan-peraturan seperti Peraturan Daerah dan Peraturan Kepala Daerah, serta memiliki kewenangan untuk merencanakan, melaksanakan, mengawasi, mengendalikan, melaporkan dan mengevaluasi penyelenggaraan pemerintahan daerah. Oleh karena itu, dalam penyelenggaraan

pemerintahan daerah unsur pemerintah daerah bersama-sama dengan Dewan Perwakuilan Rakyat Daerah (DPRD) menyelenggarakan pemerintahan daerah dan dibantu oleh Perangkat Daerah terkait dengan penyelenggaraan urusan pemerintah daerah.

Dalam urusan-urusan tertentu, pemerintah daerah dibantu olehunsurunsur lain seperti instansi vertikal yang ada di daerah, seperti dalam penyelenggaraan urusan umum pemerintahan dan urusan sisa lainnya. Sehubungan dengan hal tersebut, dalam Undang-Undang Nomor 23 Tahun 2014 tentang Pemerintahan Daerah perlu dibentuk suatu wadah yang disebut dengan Forum Koordinasi Pimpinan Daerah atau yang disingkat dengan FORKOPIMDA.

Dahulunya FORKOPIMDA ini disebut dengan unsur Musyawarah Pimpinan Daerah atau yang disingkat dengan MUSPIDA, dalam melaksanakan fungsinya FORKOPIMDA ini masih menjumpai berbagai permasalahan, seperti sumber anggaran, pengelolaan FORKOPIMDA, struktur kelembagaan
FORKOPIMDA, dan lain sebagainya. Oleh karena itu, penulis tertarik mengangkat permasalahan ini kedalam suatu bentuk tulisan dengan judul: "Fungsi Forum Koordinasi

Daerah

Dalam

Pemerintahan

Indonesia"

Pimpinan

(Forkopimda)

Sistem

\section{Pembahasan}

\section{Historis FORKOPIMDA}

Dalam penyelenggarakan urusan pemerintahan daerah, pemerintah daerah tentunya tidak dapat melaksanakannya secara sendiri, khususnya urusan-urusan yang terkait dengan urusan pemerintahan umum. Pemerintah daerah membutuhkan bantuan dari Dewan Perwakilan Rakyat Daerah (DPRD), instansi vertikal dan unsur terkait lainnya. Oleh karena itu, untuk menyelenggarakan urusan pemerintahan umum tersebut perlu dibentuk suatu badan yang pada Undang-Undang Nomor 23 Tahun 2014 tentang Pemerintahan Daerah disebut dengan Forum Koordinasi Pimpinan daerah atau yang disingkat dengan FORKOPIMDA.

Secara historis, pada masa pemerintahan orde baru dengan diberlakukannya Undang-Undang Nomor 5 Tahun 1974 tentang PokokPokok Pemerintahan Di Daerah, wadah yang hampir sama dengan FORKOPIMDA adalah Musyawarah Pimpinan Daerah atau yang disingkat dengan MUSPIDA. Keberadaan MUSPIDA ditetapkan dengan Keputusan Presiden Republik Indonesia Nomor 10 Tahun 1986 tentang Musyawarah Pimpinan Daerah (MUSPIDA). 
Muspida menurut Pasal 1 Keputusan Presiden Republik Indonesia Nomor 10 tahun 1986, adalah; "Musyawarah pimpinan daerah yang selanjutnya disingkat dengan MUSPIDA, adalah suatu forum konsultasi dan koordinasi antara Gubernur Kepala Daerah Tingkat I dan Bupati/Walikotamadya Kepala daerah Tingkat II dengan pejabat-pejabat Angkatan Bersenjata Republik Indonesia (ABRI) di daerah serta aparatur-aparatur pemerintah lainnya, dalam rangka mewujudkan dan memelihara stabilitas nasional dan pembangunan Nasional di daerah.

Sedangkan yang dimaksud dengan Musyawarah Pimpinan Daerah yang disingkat dengan MUSPIDA menurut Ateng Syarifudin (1993;119), adalah; "Suatu forum konsultasi dan koordinasi antara Gubernur Kepala Daerah Tingkat I dan Bupati/Walikotamadya Tingkat II dengan pejabat-pejabat Angkatan Bersenjata Republik Indonesia (ABRI) di daerah serta aparatur pemerintah lainnya, dalam rangka mewujudkan dan memelihara stabilitas nasional dan pembangunan nasional di daerah."

Selanjutnya, berkaitan dengan MUSPIDA menurut Bayu Surianingrat dalam Sadu Wasistiono (2010;17), bahwa; "Kebijaksanaan pemerintah oleh Gubernur Kepala daerah dimusyawarahkan dalam MUSPIDA, musyawarah dilaksanakan atas dasar gotongroyong dan dalam suasana kekeluargaan yang dipimpin oleh hikmah kebijaksanaan. Pangkal tolak musyawarah adalah persatuan dan kesatuan dengan maksud untuk memecahkan segala masalah. Segala kebijaksanaan harus ditempu oleh Ketua dan para anggota MUSPIDA untuk mencapai permufakatan dan kebulatan pendapat. Dengandemikian kesatuan dan persatuan penyelenggaraan pemerintahan di daerah dan peningkatan efisiensi semua aparatur pemerintah di daerah dapat terjamin sebagaimana yang diharapkan."

Wadah yang menampung atau yang dijadikan tempat musyawarah pimpinan daerah atau yang disebut dengan MUSPIDA ini juga dibentuk pada tingkat kecamatan yang disebut dengan Musyawarah Pimpinan Kecamatan atau yang disingkat dengan MUSPIKA, yang berfungsi untuk membantu camat dalam melaksanakan urusan-urusan pemerintahan khususnya tugas umum pemerintahan ditingkat pemerintah kecamatan.

Dalam perkembangan selanjutnya, dengan diberlakukannya Undang-Undang Nomor 23 Tahun 2014 tentang pemerintahan daerah, maka forum yang mempersatukan unsur pimpinan daerah yang sebelumnya (masa UU Nomor 5 Tahun 1974) disebut dengan MUSPIDA tersebut berganti dengan Forum Koordinasi Pimpinan Daerah atau yang disingkat dengan FORKOPIMDA. Forum koordinasi unsur pimpinan ini juga dibentuk di tingkat kecamatan yang disebut dengan Forum Koordinasi Pimpinan Kecamatan atau yang disingkat dengan FORKOPIMCAM, yang berfungsi untuk membantu camat dalam menyelenggarakan urusanurusan pemerintahan khususnya urusan pemerintahan umum di tingkat kecamatan yang dilimpahkan 
kewenangannya

oleh

Bupati/Walikota.

\section{Kelembagaan FORKOPIMDA}

Keberadaan Forum Koordinasi Pimpinan Daerah (FORKOPIMDA) ini sangat diperlukan olehpemerintah daerah, khususnya untuk membantu pemerintah daerah dalam melaksanakan urusan pemerintahan umum, seperti dinyatakan pada Pasal 1 point (18) Undang-Undang Nomor 23 Tahun 2014 TentangPemerintahan Daerah, yakni; "Forum Koordinasi Pimpian Daerah yang selanjutnya disingkat dengan FORKOPIMDA adalah forum yang digunakan untuk membahas penyelenggaraan urusan pemerintahan umum".

Urusan Pemerintahan Umum menurut Pasal 9 ayat (5) Undang-

Undang Nomor 23 Tahun 2014 adalah urusan pemerintahan yang menjadi kewenangan Presiden yang sebagai kepala Pemerintahan". Urusan pemerintahan umum tersebut selanjutnya dilimpahkan kewenangannya oleh Presiden kepada Gubernur dan Bupati/Walikota, dan selanjutnya Bupati/Walikota melimpahkan kewenangan urusan pemerintahan umum tersebut kedapa Camat.

Menurut Rahyunir Rauf (2016;142-143), bahwa; "Urusan pemerintahan umum merupakan urusan pemerintahan yang tidak termasuk dalam urusan absolut dan tidak termasuk dalam urusan konkuren atau urusan otonomi daerah. Urusan pemerintahan umum dilaksanakan oleh Gubernur dan Bupati/Walikota di wilayah kerjanya masing-masing, dan dalam pelaksanaannya dapat meminta bantuan dari isnstansi vertikal diwilayahnya masing-masing". Sehubungan dengan pelaksanaan urusan pemerintahan umum tersebut di daerah dibentuk Forum Koordinasi Pimpinan Daerah (FORKOPIMDA), seperti dinyatakan pada Pasal 26 UndangUndang Nomor 23 Tahun 2014, yakni; "Untuk menunjang kelancaran pelaksanaan urusan pemerintahan umum, dibentuk FORKOPIMDA Provinsi, $\quad$ FORKOPIMDA Kabupaten/Kota, dan FORKOPIM Kecamatan.

$\begin{array}{ccc}\text { FORKOPIMDA } & \text { Provinsi } \\ \text { diketuai } & \text { oleh } & \text { Guberbur, }\end{array}$
FORKOPIMDA kabupaten diketuai oleh Bupati, dan FORKOPIMDA Kota diketuai oleh Walikota serta FORKOPIM Kecamatan diketuaioleh Camat. Anggota FORKOPIMDA daerah Provinsi dan Kabupaten/Kota terdiri atas;

1. Pimpinan DPRD

2. Pimpinan Kepolisian

3. Pimpinan Kejaksaan

4. Pimpinan Satuan Teritorial TNI di daerah

Sedangkan anggota dari FORKOMPIM Kecamatan, terdiri dari unsur sebagai berikut;

1. Pimpinan Kepolisian

2. Pimpinan Kewilayahan TNI di Kecamatan.

Dalam implementasinya FORKOPIMDA Provinsi, FORKOPIMDA kabupaten/Kota dan FORKOPIM Kecamatan dapat mengundang pimpinan instansi vertikal sesuai dengan masalah yang dibahas.

\section{Fungsi FORKOPIMDA}

Secara yuridis, forum koordinasi pimpinan daerah dan 
kecamatan membantu pemerintah daerah dan kecamatan dalam membahas dan melaksakan urusan pemerintahan umum diwilayah kerjanya. Urusan pemerintahanumum terdiri dari 7 jenis, seperti yang diatur pada Pasal 25 Undang- Undang Nomor 23 Tahun 2014 Tentang Pemerintahan Daerah yang terdiri dari;

1. Pembinaan wawasan kebangsaan dan ketahanan nasional dalam rangka memantapkan pengamalan Pancasila, pelaksanaan UndangUndang Dasar Negara Kesatuan Republik Indonesia Tahun 1945, pelestarian Bhineka Tunggal Ika serta pemertahanan dan pemeliharaan keutuhan Negara Kesatuan Republik Indonesia.

2. Pembinaan persatuan dankesatuan bangsa

3. Pebinaan kerukunan antarsukudan intrasuku, umat beragama, rasdan golongan lainnya guna mewujudkan stabilitas keamanan loka, regional dan nasional.

4. Penanganan konflik sosial sesuai dengan ketentuan peraturan perundang-undangan.

5. Koordinasi pelaksanaan tugas antarinstansi pemerintahan yang ada diwilayah daerah provinsi dan daerah kabuaten/kota untuk menyelesaikan permasalahanyang timbul dengan memperhatikan prinsip demokrasi, hak asasi manusia, pemerataan, keadilan, keistimewaan dan kekhususan, potensi serta keanekaragaman daerah sesuai dengan ketentuan peraturan perundang-undangan.

6. Pengembangan kehidupan demokrasi berdasarkan Pancasila, dan
7. Pelaksanaan semua urusan pemerintahan yang bukan merupakan kewenangan daerah dan tidak dilaksanakan oleh instansi vertikal.

Oleh karena itu, dapatdiketahui bahwa fungsi Forum Koordinasi Pimpinan Daerah ini adalah untuk menunjang pemerintah daerah dalam pelaksanaan urusan pemerintahan umum. Urusan pemerintahan umum tersebut lebih berorientasi kepada pembinaan, pengembangan, koordinasi dan penanganan konflik masyarakat di daerah.

Pelaksanaan

urusan pemerintahan umum dibiayai melalui anggaran pendapatan dan belanja Negara (APBN) seperti dinyatakan pada Pasal 25 ayat (5) UndangUndang Nom0r 23 Tahun 2014, bahwa; Gubernur dan Bupati/Walikota dalam melaksanakan urusan pemerintahan umum dibiyai dari APBN.

Demikian juga untuk penyelenggaraan urusan pemerintahan umum di tingkat pemerintah kecamatan juga dibiayai melalui Anggaran Pendapatan dan Belanja Negara (APBN), karena Bupati/Walikota dalam melaksanakan urusan pemerintahan umum di tingkat kecamatan dapat melimpahkan kewenangannya kepada camat.

Namun secara realita walaupun penyelenggaraan urusan pemerintahan secara jelas dinyatakan dalam Undang-Undang Nomor 23 Tahun 2014 pembiayaannya melalui Anggaran Pendapatan dan Belanja Negara (APBN), namun sampai saat belum dibiayai melalui APBN seperti yang diamanahkan oleh Undang- 
Undang, hal ini disebabkan karena belum ada peraturan pemerintah yang mengatur khusus tentang FORKOPIMDA, hal ini tentunya secara tidak langsung dapat menghambat pemerintah daerah dan FORKOPIMDA dalam penyelenggaraan urusan penerintahan umum yang dilimphakan oleh Presiden.

\section{Kesimpulan}

1. Forum Koordinasi Pimpinan Daerah diubentuk berdasar Undang-Undang Nomor 23 tahun 2014 tentang Pemerintahan Daerah.

2. Secara historis Forum Koordinasi Pimpinan daerah (FORKOPIMDA) dahulunya dalam bentuk Musyawarah Pimpinan Daerah atau yang disingkat MUSPIKA

3. Fungsi Forum koordinasi Pimpinan Daerah adalah suatu wadah untuk dapat menunjang pelaksanaan urusan pemerintahan umum oleh pemerintah daerah.

4. Kegiatan yang terkait dengan FORKOPIMDA dibiayai memalui Anggaran pendapatan dan Belanja Negara.

\section{Saran}

1. Disarankan kepada pemerintah untuk secepatnya mengeluarkan peraturan pemerintah tentang Forum Komunikasi Pimpinan Daerah, agar Forkompimda memiliki aturan yang jelas dalam fungsi membantu penerintah daerah dalam menyelenggarakan urusanpemerintahan umum yang dilimpahkan oleh Presiden.
2. Disarankan kepada daerah provinsi dan kabupaten/kota untuk berinisiatif dalam menanggulangi biaya penyelenggaraan urusan pemeritahan umum yang dilaksanakan secara bersama-sama dengan unsur Forum Koordinasi Pimpinan daerah.

\section{Daftar Kepustakaan}

Ateng Syarifudin, 1993, Pengaturan Koordinasi Pemerintahan di Daerah, Citra Aditya Bakti, Bandung.

Rahyunir Rauf, 2016, Posisi DPRD Dalam Sistem Pemerintaan Daerah, Marpoyan Tujuh, Pekanbaru.

Sadu Wasistiono, 2010, Persepsi Pejabat Pemerintahan Di Daerah Tentang Keberadaan Musyawarah Pimpinan Daerah, (hasil Penelitian) Jakarta.

di Keamatan, M. P. N. S., \& Hulu, S. Evaluasi Pelaksanaan Peraturan Pemerintah Nomor 45 Tahun 2007 Tentang Persyaratan dan Tata Cara Pengangkatan Sekretaris Desa.

Ispik, A., Yogia, M. A., Wedayanti, M. D., \& Zainal, Z. (2021). The Influence of Discipline on Performance of Employees Office of the Ministry of Religion. Pekanbaru City.

Subhayano, T., Yogia, M. A., Wedayanti, A. A. P. M. D., \& Zainal, M. L. H. (2021). Good Governance in Maintaining Peace and Order at Pangkalan Kerinci District. Pelalawan Regency.

Ispik, A., Yogia, M. A., Purwati, A. A., Wedayanti, M. D., \& Zainal, M. 
L. H. (2021). Analysis of Benefits, Discipline and Leadership Style in improving Employee Performance of the Ministry of Religion in Pekanbaru, Indonesia.

Nasri, H., Nurman, N., Azwirman, A., Zainal, Z., \& Riauan, I. (2022). Implementation of collaboration planning and budget performance information for special allocation fund in budget planning in the regional development planning agency of Rokan Hilir regency. International Journal of Health Sciences (IJHS) Ecuador, 6(S4), 639-651.

Munir, A., Wahyudi, S., \& Zainal, Z. (2020). Tinjauan Kriminologi Terhadap Sensual Marketing Sebagai Strategi Pemasaran Produk Yang Diperankan Oleh Sales Promotion Girl Di Kota Pekanbaru. Wedana: Jurnal Kajian Pemerintahan, Politik dan Birokrasi, 6(2), 21-35.

Subhayano, T., Yogia, M. A., Wedayanti, M. D., \& Zainal, Z. (2021). The Role of the Camat in Coordinating the Administration of Peace and Order in Pangkalan Kerinci District Pelalawan Regency.

Suwaryo, H. U., \& Redjo, H. S. I. (2018). Transformasi Hubungan Pemerintah Pusat Dan Pemerintah Daerah Dalam Pemberian Izin Hutan Tanaman Industri Bagi Swasta Di Provinsi Riau Tahun 2010-2015.

Wicaksono, A. (2022, April). Peatlands Restoration Policies in Indonesia: Success or Failure? In IOP Conference Series: Earth and

Environmental
Science (Vol. 995, No. 1, p. 012068). IOP Publishing.

Yogia, A. S. M. A., Rahman, Z. M. D. W. K., \& Purwati, A. A. (2021). Leadership of Tourism and Culture Department in Development of Cultural Reserves at District Kuantan Singingi.

Zainal, Z., Rambey, R. R., \& Rahman, K. (2021). Governance of Household Waste Management in Pekanbaru City. MIMBAR: Jurnal Sosial dan Pembangunan, 37(2).

Halim, N. A., Rosidi, I., Haris, A., Yesicha, C., \& Riauan, M. A. I. Media dan Politik.

Riauan, M. A. I., Aziz, A., \& Nurman, N. (2020). Analisis Framing" Aksi Bela Islam" sebagai Dakwah Islam di Riau Pos (A Framing Analysis of" Islam Defense Action" as Islamic Dakwah on Riau Pos Newspaper). Jurnal Dakwah Risalah, 31(1), 35-47.

Riauan, M. A. I., Qurniawati, E. F., Aslinda, C., \& Aziz, A. (2020). Konstruksi Realitas Pada Pesan Politik Calon Walikota Pekanbaru di Riau Pos. ETTISAL: Journal of Communication, 5(1).

Riauan, M. A. I., Kholil, S., \& Sikumbang, A. T. (2019). Islamic Symbols on Political Messages in Newspapers in Riau (Study in Regional Head Election 2017). Budapest International Research and Critics InstituteJournal (BIRCI-Journal), 2(1), 254-262.

Riauan, M. A., Sari, G. G., Aslinda, C., \& Qurniawati, E. F. (2018). 
Konstruksi Makna

Ketergantungan dalam Perilaku Merokok. Relasi Negara Industri Dan Masyarakat Dalam Perspektif Komunikasi, 171.

Riauan, M. A. I., \& Shasrini, T. (2017). Dampak Komunikasi Terapeutik terhadap Citra Pelayanan Kesehatan (Studi Kasus di Rumah Sakit Umum Daerah Arifin Achmad Pekanbaru). Jurnal The Messenger, 9(1), 31-43.

Riauan, M. A. I. (2016). Figur Politik Calon Walikota Pekanbaru Septina Primawati Rusli dan Erizal Muluk Pada Pemilukada Kota Pekanbaru 2011. Medium, 4(2).

Riauan, M. A. I. (2013). Penggunaan Teknologi Komunikasi dalam Penerapan Good Governance. Jurnal Kajian Pemerintahan, 2(2), 102-107.

Riauan, M. A. I. (2012). Studi Komparatif Aktivitas Humas Antara Pemerintah Provinsi Riau dengan PT. Chevron Pacific Iindonesia. Medium, 1(1).

Sari, G. G., Wirman, W., \& Riauan, M. A. (2018). Pergeseran Makna Tradisi Bakar Tongkang Bagi Generasi Muda Tionghua di Kabupaten Rokan Hilir Provinsi Riau. 